\title{
SOBRE PENSAMENTO E LINGUAGEM Wilhelm Von Humboldt
}

Tradução e apresentação: Antonio Ianni SEGATTO

\section{Apresentação}

\section{Breve nota sobre Wilhelm von Humboldt e a filosofia alemã da linguagem}

Wilhelm von Humboldt, na esteira de autores como Johann Georg Hamann e Johann Gottfied Herder, inaugura uma das versões daquela tradição de pensamento conhecida sob a rubrica de "virada lingüística". Mais de um século antes da consolidação dessa tradição, esses autores já realizavam uma crítica decisiva da concepção de linguagem vigente em quase toda a história da filosofia e propunham uma nova maneira de conceber as relações entre pensamento, razão e linguagem. Basta para atestá-lo, a recordação seja dos famosos bordões de Hamann segundo os quais "razão é linguagem, logos" ou "sem a palavra, não há razão - nem mundo", seja da frase de Herder segundo o qual "a linguagem é o critério da razão".

De modo geral, é possível dizer que são dois os traços fundamentais dessa virada linguística avant la lettre: em primeiro lugar, como consequência da superação da concepção tradicional da linguagem enquanto "instrumento", enquanto simples meio para a expressão de pensamento pré-linguísticos, ela é considerada como elemento constitutivo do pensamento e do conhecimento e, nessa medida, é considerada como condição de possibilidade tanto da objetividade da experiência quanto da intersubjetividade da comunicação; em segundo lugar, essa nova concepção de linguagem conduz a uma neces-

1 Antonio Ianni Segatto é Doutorando em Filosofia na Universidade de São Paulo e bolsista da FAPESP. 
sária destranscendentalização da razão: a linguagem manifesta-se sempre em línguas particulares e históricas e não permite, por isso, uma separação estrita entre o transcendental e o empírico, entre o a priori e o a posteriori.

O impulso para essa reviravolta é, não por acaso, a crítica, ou melhor, a metacrítica da razão pura kantiana. Hamann, que teve acesso às primeiras provas da Crítica da razão pura, redige, em 1784, uma Metacrítica sobre o purismo da razão. Herder, que foi colaborador de Hamann, é autor de uma Metacrítica da Crítica da razão pura (1799). No que diz respeito ao primeiro autor, é possível localizar essa metacrítica em um ponto preciso: ele situa a raiz comum entre sensibilidade e entendimento, buscada por Kant, justamente na linguagem. Se tivesse se perguntado "como a capacidade de pensar é possível?", Kant teria notado que "a faculdade de pensar repousa sobre a linguagem" (Hamann, 1992, p. 144). Com esse passo, Hamann "converte a linguagem em uma instância que concorre com o 'eu transcendental' (ou a 'consciência em geral'), na medida em que ela pode reivindicar para si a autoria dos rendimentos constitutivos da experiência (ou do 'mundo') falsamente atribuídos àquele" (Lafont, 1994, p. 272).

Humboldt, por seu turno, dá um passo além. Ele propõe uma compreensão da linguagem não apenas como um sistema acabado, mas como atividade. Em suas palavras: "é preciso considerar a linguagem não como um produto morto (todtes Erzeugtes), mas, sobretudo, como uma produção (Erzeugung) (...) Em si mesma, a linguagem não é um produto (Ergon), mas uma atividade (Energeia)" (Humboldt, 2002, p. 416 e 418). É interessante notar, nessa compreensão da linguagem como atividade, que seu aspecto criador comparece tanto em um ponto de vista semântico quanto em um ponto de vista pragmático. E é justamente esse fato que faz de suas reflexões um marco importante não apenas para a linguística, mas também para a filosofia contemporânea. Conforme a caracterização precisa de Cristina Lafont:

Humboldt leva a cabo uma mudança de paradigma que afeta não apenas a linguística, cujo desenvolvimento no século XX revela as consequências dessa mudança de maneira bastante clara, mas também a filosofia, para a qual a linguagem (vista como sistema de signos objetificados) nunca teve uma dimensão filosófica. Além disso, a mudança de paradigma levada a cabo por Humboldt ocorre em duas dimensões diferentes. Em sua dimensão cognitivo-semântica, essa mudança consiste em encarar a linguagem não como um mero sistema de signos, não como algo objetificável (intramundanamente), mas como algo constitutivo da atividade de pensar, como a própria condição de possibilidade dessa atividade. A linguagem é, então, elevada a um estatuto quasi-transcendental, que reivindica contra a subjetividade a autoria das operações constitutivas da visão de mundo do sujeito (...) Em sua dimensão comunicativo-pragmática, a mudança consiste em ver esse caráter constitutivo da linguagem como o resultado de um processo ou atividade: especificamente, a ati- 
vidade de falar. Nesse sentido, a linguagem se torna a garantia da intersubjetividade da comunicação, a condição de possibilidade do entendimento entre falantes (Lafont, 1999, p. 17-18).

No que se refere à primeira dimensão, a compreensão da linguagem como atividade revela-se no fato de que por meio dela criam-se novos "conceitos", novos "conteúdos" por meio dos quais o mundo se faz acessível. Humboldt, reportando-se e opondo-se a Kant, refere-se a essa atividade como uma síntese: "desde o primeiro elemento, a geração da linguagem é um processo sintético - e isso no sentido estrito da palavra - que cria algo que não existia em nenhuma de suas partes" (Humboldt, 2002, p. 473). No que se refere à segunda dimensão, a compreensão da linguagem como atividade revela-se na idéia da unificação através do diálogo. No lugar do "eu penso" kantiano - associado à unidade transcendental da apercepção -, Humboldt coloca a intersubjetividade, representada pelas diferentes perspectivas dos participantes da comunicação, que buscam alcançar um entendimento entre si sobre algo no mundo.

É certo que Humboldt em algumas passagens parece conceder uma primazia à primeira dimensão. Podemos lembrar, a título de exemplo, um dos momentos em que ele ressalta o nexo entre a "forma interna" da língua e uma determinada imagem do mundo que ela impõe aos povos e nações. No opúsculo sobre as diferenças na estrutura da linguagem humana, ele escreve: "cada língua traça ao redor da nação a que pertence um círculo do qual só é possível sair na medida em que ao mesmo tempo se passa para outro círculo de uma outra língua" (Humboldt, 2002, p. 224-5). Mas é certo também que em outros momentos ele assinala o primado da dimensão comunicativo-pragmática da linguagem: "o diálogo que verdadeiramente engrena uns aos outros, que troca ideias e sensações é, por assim dizer, o centro da linguagem" (Humboldt, 2002, p. 81).

Não se pode, pois, sobrepor uma dimensão à outra como parecem fazer Heidegger, Gadamer e, recentemente, Charles Taylor. Ao contrário, é preciso examinar como ambas se combinam no mesmo quadro. Assim, é preciso compreender a divisão de trabalho entre a dimensão cognitivo-semântica e a dimensão comunicativo-pragmática. É preciso compreender que, paralelamente a certo particularismo semântico, coloca-se um universalismo da conversação. Seja como for, não há como não reconhecer que Humboldt foi responsável, nas palavras de um de filósofo contemporâneo que reivindica a herança do autor, por desenhar os contornos de uma "arquitetônica da linguagem que até hoje permaneceu decisiva para uma transformação pragmática da filosofia kantiana" (Habermas, 1999, p. 76).

Para terminar essa breve apresentação, uma palavra sobre a circunstância de composição do opúsculo traduzido aqui. "Sobre pensamento e lin- 
guagem" é o primeiro dos escritos de Humboldt dedicados à linguagem. Escrito entre 1795 e 1796, ele é uma reação ao texto "Da faculdade de falar e da origem da linguagem" de Fichte. Para este, conforme a caracterização de Rubens Rodrigues Torres Filho, "o nascimento da linguagem não é a abertura do espaço da representação, mesmo porque a representação já estava na base da ação sobre o mundo, bem antes de qualquer linguagem" (Torres $\mathrm{F}^{\circ}, 1975$, p. 152). E isso porque a linguagem é simplesmente "a expressão de nossos pensamentos por signos arbitrários" e a "faculdade de falar é a capacidade de designar arbitrariamente seus pensamentos" (Fichte, 1846, p. 302 e 303). Em outras palavras, a função da linguagem é meramente a expressão, com um propósito específico, de algo prévio, isto é, a designação de pensamentos pré-linguísticos que já estão constituídos antes de seu advento. Não será difícil ao leitor notar que o texto de Humboldt reage justamente à ideia de que a linguagem surge depois da atividade de representação, pois, como assinalamos, de um ponto semântico, a linguagem como atividade revela-se no fato de que por meio dela criam-se novos "conceitos", novos "conteúdos", nos quais o mundo se faz acessível. Em suma, a linguagem é parte constitutiva da atividade de representar.

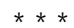

\section{Sobre pensamento e linguagem ${ }^{2}$}

1. A essência do pensamento consiste no refletir, i. e., na distinção entre o pensante e o pensado.

2. A fim de refletir, o espírito, em sua atividade progressiva, tem que parar por um instante, apreender em uma unidade o que fora representado e, desse modo, contrapô-lo a si como objeto. ${ }^{3}$

3. Ele volta a comparar umas às outras as unidades, que, por essa via, ele pode formar de maneira variada, as separa e vincula conforme sua necessidade.

2 Título original: "Über Denken und Sprechen". Traduzido a partir da versão publicada em HUMBOLDT, Wilhelm von. Schriften zur Sprache. Herausgegeben von Michael Böhler. Stuttgart: Philipp Reclam, 2007, p. 3-5.

3 Em uma nota a sua tradução da Doutrina-da-Ciência de Fichte, Rubens Rodrigues Torres Filho chama a atenção para a seguinte peculiaridade: "a língua alemã mostra melhor porque ob-jeto (GEGENstand) depende da ação de o-por (GEGENsetzen). Gegen significa 'contra'" (FICHTE, Johann Gottlieb. A Doutrina-da-Ciência de 1794 e outros escritos (Col. Os Pensadores). Tradução e notas de Rubens Rodrigues Torres Filho. São Paulo: Abril Cultural, 1980, p. 51). Humboldt, tendo em vista a obra de Fichte, se vale da mesma peculiaridade ao utilizar aqui o par: Gegenstand/ entgegenstellen. No item 4, ele utiliza o par Gegenstand/entgegensetzen; e, no item 6, ele utiliza um terceiro par: Gegenstand/gegenüberstellen (N. do T.). 
4. A essência do pensamento consiste, pois, em produzir divisões em seu próprio curso; formar, por meio disso, totalidades a partir de porções determinadas de sua atividade; e opor ao sujeito pensante essas formações, cada uma por si mesma, mas conjuntamente, como objetos.

5. Nenhum pensamento, nem o mais puro, pode ocorrer sem o auxílio das formas de nossa sensibilidade; apenas com elas podemos apreendê-lo e, ao mesmo tempo, retê-lo.

6. A designação sensível de unidades, na qual determinadas porções do pensamento são unificadas, para que sejam contrapostas ao sujeito como partes de outras partes de totalidades maiores, i. e., como objetos, é chamada, na compreensão mais vasta da palavra, linguagem.

7. A linguagem começa, por isso, imediata e simultaneamente ao primeiro ato da reflexão, e, assim que o homem acorda para a consciência-desi a partir das profundezas do impulso, por meio do qual o sujeito engole o objeto, ali está a palavra - ao mesmo tempo, o primeiro travo ${ }^{4}$ que o homem dá a si mesmo, para de repente parar, situar-se e orientar-se.

8. O homem que busca a linguagem busca sinais, sob os quais, em virtude das divisões que produz em seu pensamento, ele pode apreender totalidades como unidades. Para tais sinais, os fenômenos compreendidos no tempo são mais acessíveis que os compreendidos no espaço.

9. Os contornos das coisas dispostas umas ao lado das outras se misturam facilmente para a imaginação, assim como para a visão. No curso do tempo, ao contrário, um limite determinado separa o instante presente do passado e do futuro. Entre ser e já-não-ser, não há confusão possível.

10. O olho, imediatamente e por si mesmo, não seria capaz de determinar nenhum outro limite além daqueles entre diferentes cores, mas não por meio dos contornos entre diferentes objetos. A essa determinação chega-se ou bem por meio da mão que toca ou bem por meio da mão que acompanha o corpo por um período de tempo ou bem por meio do movimento com o qual um objeto se aparta de outro. Conforme uma ou outra, o olho constrói suas conclusões analógicas.

11. As mais nítidas de todas as mudanças no tempo são aquelas produzidas pela voz. Elas são, ao mesmo tempo, as mais curtas e, provindo do próprio homem com a respiração que a anima e esvaindo-se num piscar de olhos, são de longe as mais vivas e mais impressionantes.

4 Como Humboldt tem em vista o obra de Fichte, o termo alemão Anstoß foi traduzido por "travo", seguindo a opção de Rubens Rodrigues Torres Filho em sua tradução da Doutrina-da-Ciência. Para Fichte, o entrave à ação do eu era o ponto de partida para a atividade reflexionante: o eu põe o não-eu, etc. Mutatis mutandis isso também parece valer para Humboldt, mas a atividade reflexionante não dispensa, como para Fichte, a linguagem (N. do T.). 
12. Os sinais lingüísticos são, por isso, necessariamente sons e, conforme a analogia secreta entre todas as faculdades do homem, ele teve, tão logo tenha reconhecido claramente um objeto como separado de si, que pronunciar imediatamente o som que deveria designá-lo.

13. A mesma analogia vai mais longe. Quando o homem procurava sinais lingüísticos, o entendimento tinha a tarefa de diferenciar. Ele construía outras totalidades, que não eram efetivamente coisas, mas conceitos, os quais permitiam uma ação livre, repetidas separações e novas ligações. Em conformidade a isso, a língua (Zunge) também escolheu sons articulados, que consistiam de elementos, os quais possibilitavam múltiplas novas combinações.

14. Tais sons não existem no resto natureza, pois ninguém, exceto o homem, convida seus pares para o entendimento por meio do pensamento compartilhado; no máximo, convida para a ação por meio da sensação compartilhada.

15. O homem, portanto, não acolhe em sua linguagem nenhum som natural isolado, em estado bruto, tal como é, mas sempre forma apenas sons articulados semelhantes aos naturais.

16. Ele diferencia muito bem seus próprios gritos relativos às sensações da linguagem; e, nisso, a sensibilidade conduz muito corretamente mesmo os mais civilizados. Se não puder mais pensar, se já não puder separar-se do objeto na representação, então emite um som natural; caso contrário, fala e eleva o tom de acordo com suas afecções.

\section{Referências bibliográficas}

FICHTE, Johann Gottlieb. Von der Sprafähigkeit und dem Ursprung der Sprache. Sämmtliche Werke, Achter Band. Berlin: Verlag von Veit und Comp., 1846, p. 301-341.

HABERMAS, Jürgen. Hermeneutische und analytische Philosophie. Zwei komplämentare Speilarten der linguistischen Wende. Wahrheit und Rechtfertigung. Frankfurt am Main: Suhrkamp, 1999, p. 65-101.

HAMANN, J. G. Metacrítica sobre o purismo da razão. GIL, F. (org.). Recepção da Crítica da razão pura: antologia de escritos sobre Kant (1786-1844). Lisboa: Fundação Calouste Gulbenkian, 1992, p. 139-153.

HUMBOLDT, Wilhelm von. Schriften zur Sprachphilosophie (Werke III). Darmstadt: Wissenchaftliche Buchgesellchaft, 2002.

LAFONT, Cristina. "Apertura del mundo" y referencia. VIEJA, M. T. L. de la (ed.). Figuras del logos: entre la filosofía y la literatura. México D. F.: Fondo de Cultura Económica, 1994, p. 271-288.

The linguistic turn in hermeneutic philosophy. Cambridge, Mass.: MIT Press, 1999.

TORRES F $F^{\circ}$, Rubens Rodrigues. O espírito e a letra: a crítica da imaginação pura em Fichte. São Paulo: Ática, 1975. 